\title{
Living with Bodily Changes after Weight Loss Surgery Women's Experiences of Food and “Dumping”
}

Karen Synne Groven, Institute of Health and Society, University of Oslo, Norway Email: k.s.groven@medisin.uio.no

Gunn Engelsrud, Department of Physical Education, Norwegian School of Sports Science, Oslo, Norway / Institute of Health and Society, University of Oslo, Norway

Målfrid Råheim, Department of Public Health and Primary Care, University of Bergen, Norway

\section{Abstract}

In this article we explore women's experiences of “dumping” following weight loss surgery. The empirical material is based on individual interviews with 22 Norwegian women. To further analyze their experiences, we build primarily on the phenomenologist Drew Leder`s notion of the "inner body." Additionally, Simone de Beauvoir and Merleau-Ponty's perspectives of the lived body occupy a prime framework for shedding light on different dimensions of bodily changes. The following three core themes were identified: Experiences of illness in conjunction with eating; Learning to relate to changes in the inner body and; Feelings of losing and regaining control. In different, though interconnected ways, these themes encompass an ongoing challenge in the women's lives after the surgery: namely their efforts to establish new eating habits while at the same time working hard to relate to their changed and changing inner body, and especially to the phenomenon of "dumping". The results points to a dilemma: namely that the gastric bypass procedure is an operation that irreversibly alters the anatomy and physiology of a healthy stomach, whereas the individual's eating habits cannot be situated in or reduced to a particular organ, but are endemic to the lived body and its history. This insight might be of importance in the understanding of the complexity of the changes and challenges the women go through after weight loss surgery.

\section{Introduction}

Persons diagnosed as obese turn increasingly to surgery as a means of losing weight. In the United States the number of bariatric surgeries increased nearly 450\% between 1998 and 2002, and doubled between 2002 and 2004 to more than 125,000 adults (Wysoker, 2005). This pattern can also be seen in Scandinavian countries. In Norway the number of weight loss surgeries increased from 400 in 2005 to more than 2000 in 2010 (Hofsbø et al., 2011). ${ }^{1}$ Additionally, a

\footnotetext{
${ }^{1}$ Ministry of Health and Care Services
} 
large number of Norwegians are seeking such operations abroad. It should also be noted that the majority of those seeking weight loss operations are women. In a recent study of "morbidly" obese patients undergoing surgery in Norway, more than 70 percent were women (Jakobsen, Hofsbo, Roislien, Sandbu, \& Hjelmesaeth, 2010). In the United States, recent studies indicate that more than 80 percent of patients undergoing weight loss surgery are women (Martin, Beekly, Kjorstad, \& Sebesta, 2010).

Although there are more than 20 different surgical procedures for obesity, the most common is the gastric bypass procedure (Ferraro, 2004; Fisher \& Schauer, 2002). This procedure provides a physical limitation to the amount the patient can eat, and it also reduces food absorption after ingestion, resulting in more rapid and dramatic weight loss compared to other procedures (Fisher \& Schauer, 2002; Ogden Clementi \& Aylwin, 2005; Burgmer et al., 2009). However, the gastric bypass is also accompanied by side-effects, the most common of which is termed "dumping syndrome". Symptoms associated with "dumping” include irregular heartbeat, drop in blood pressure, diarrhea, and nausea. According to recent studies, such symptoms are due to a series of physiological processes that are triggered when food reaches the small intestine too quickly (Tack et al., 2009). Moreover, rapid delivery of carbohydrates to the small intestine is reported to cause excessive insulin secretion. Whether these processes cause "dumping" symptoms - or are a consequence of it - is, however, still a matter of controversy (Deitel, 2008). To avoid dumping symptoms, patients are encouraged to eat small and frequent meals, preferably every three to four hours, as well as avoid foods containing a high carbohydrate load (Ukleia, 2005). However, to date, research on this area has revolved around the physiological mechanisms associated with "dumping" and how these mechanisms can be dealt with from a medical perspective. Little is known about how "dumping" is experienced from a first-person perspective, namely that of the patients themselves. Thus, the aim of this article is to elaborate on women's experiences of "dumping" after having undergone a gastric bypass operation.

\section{Theoretical Framework}

As indicated in the introduction, weight loss surgery involves major bodily changes. MerleauPonty's phenomenology of the lived body offers perspectives to understand the meanings of these changes to those who live through them. In his theory, the body is seen as lived and intentional, inherent in the world. The body is regarded as fundamental in and to all human experience, and being a body subject means always already being in-the-world (Merleau-Ponty, 2002). In this sense, perception is not inside the individual like a beetle in a box, but rather in the intertwining of the organizing, sensing body and the things of the world (Langer, 1989). Additionally, Merleau-Ponty emphasizes that consciousness is never an isolated process located in a person`s brain. Rather, consciousness is embodied, so that body and self as well as body and world are intertwined (Hass, 2008).

To illuminate his conceptualization of perception as embodied, Merleau-Ponty presents several examples of pathology. In particular, he discusses at length the phenomenon of the phantom limb - the experience of still having a limb after it has been amputated. He points out that a physiological account fails to explain how a limb which is no longer physically part of the body can nevertheless be experienced. Local anesthetic does not eliminate the phenomenon, and often the missing arm or leg is experienced in the same position as it was at the time of the injury (Merleau-Ponty, 2002, pp. 86-89). Similarly, he points out that the phantom limb is not 
psychological or "mental" since the limb is still experienced even when the nerves to the brain are cut (p. 102). Merleau-Ponty argues that one needs to regard the changed body as a situation where the psychic and the physiological "gear into each other" (p. 89). Moreover, he emphasizes that the ambiguity associated with phantom limbs can be accounted for through the body`s two layers:

In the case under consideration, the ambiguity of knowledge amounts to this: our body comprises as it were two distinct layers, that of the habit-body and that of the body at this moment. In the first appear manipulatory movements which have disappeared from the second, and the problem how I can have the sensation of still possessing a limb which I no longer have, amounts to finding out how the habitual body can act as guarantee for the body at this moment. (p. 95)

As indicated in this quote, the "habit body" is associated with previous habits and experiences, whereas the "body at this moment" is linked to spontaneous experiences here and now. In this regard, the "habit body" represents a pivotal kind of bodily competence - or embodied knowledge - which is profoundly challenged in situations of bodily change. So, when a person is injured or ill, it can no longer be taken for granted. The person must learn to relate to the bodily changes, and her new life situation. Merleau-Ponty elucidates this when he discusses the process of habit acquisition.

The irreversible gastric bypass procedure changes the body's viscera located inside the women`s bodies, physically restricting the amount of food that can be consumed. Drew Leder's notions of "surface body "and "inner body" are therefore of relevance (Leder, 1990). He emphasizes that physical, physiological and social strain intertwine with the body's functional unity in ways that affects the visceral functions - including those of the stomach and intestines as well as the surface body. However, the two layers are different in terms of perception. The visceral organs which comprise the "inner" body have a greatly decreased number and variety of sensory receptors compared to the "surface" body. Consequently, the "inner" body is more difficult to control and command compared to the surface body (Leder, 1990).

Neither Merleau-Ponty nor Leder elaborates on the significance of gender in a person's experiences. In our study, we will therefore also use Simone de Beauvoir's perspective on the body as gendered (de Beauvoir, 2000). She argues that the female body - with its biological characteristics and reproductive functions - situates women differently than men. Due to their female bodies, they are likely to encounter specific challenges and demands, including bodily based experiences of the menstruation cycle and the significance of giving birth to children, as well as caring for their appearance and behaving in "proper" feminine ways. At the same time, de Beauvoir stresses that the biological body alone does not define a woman. On the contrary, she needs to make the body her own; a process that is accomplished through interaction with the woman's socially and culturally situated choices and activities (Moi, 2008). Hence, biology and culture are folded together in women's experiences, and this intertwinement is important to our exploration.

The perspectives of these three philosophers indicate that the situated, lived and gendered body bears the mark of both previous and ongoing experiences. The body is seeing and seen, touching and touched, stable and movable - constantly changing and involved in reciprocal exchange with its surroundings. 


\section{Method and Material}

One of the central goals of phenomenological research is to investigate embodied, experiential meanings (Svenaeus, 2000; Bengtsson, 2006; Finlay, 2009). We aim, in the words of Linda Finlay, for fresh, complex and rich descriptions of a phenomenon as it is concretely lived (2009, p. 6). In our exploration of the phenomenon of dumping, we have been inspired by Max van Manen's inquiry into lived experience. This approach has a retrospective design in the sense that it emphasizes reflection on experiences that are "already passed" or "lived through" (1997, pp. 10-13). Moreover, van Manen's approach is hermeneutic in the sense that he intertwines description and interpretation in an attempt to capture the "meanings" embedded in lived experience (p. 11). From this point of view, hermeneutic phenomenology encourages "a certain attentive awareness" to the seemingly "trivial dimensions" of the participants' experiences, making the researcher "thoughtfully aware of the significant" in the taken-for-granted" (p. 8). Hence, it follows that the researcher can take neither scientific explanations nor everyday experiences for granted, but must rather approach the subject matter in an explorative, dwelling and open manner.

Our study draws on interviews with 22 women, all of whom have undergone a gastric bypass procedure. They were recruited from the eastern part of Norway and were aged 24-54 years. They were living in towns, cities, and rural areas, were married, cohabiting, in a relationship, or single. The majority of the women held jobs in service and care, office work, or academia. Some were students aiming for higher education; a few were management-level supervisors with responsibility for personnel, while two were on disability benefits and had been unemployed for several years. Prior to their surgery, most of the participants had a Body Mass Index ranging from 40-55. They had all experienced being "large" and "heavy" more or less continuously for several years. And they had all gone through repeated cycles of dieting and weight loss and gain.

Inspired by van Manen's conversational approach, the first author emphasized a contextsensitive form of interpretive inquiry throughout the interview process (van Manen, 1997). Although she used a semi-structured interview guide, the conversation shifted between the researcher introducing new topics and the participant taking the lead. Underway, the women were eager to talk about their experiences with bodily sensations that they associated with the phenomenon of "dumping." This topic was usually introduced by the women themselves when they talked about their efforts to change eating habits after the surgery. The researcher, who initially knew very little about "dumping," decided to explore this phenomenon further. Kvale and Brinkman (2008) describe such an approach as "deliberate naiveté" in the sense that the researcher exhibits openness to new and somewhat unexpected phenomena (p. 28). In our study, this meant that the researcher asked follow-up questions as well as encouraging the women to elaborate on specific anecdotes or episodes that would illustrate their experiences as concretely as possible. In doing so, her intention was to devise questions and directions that facilitated lived through meanings and reflections accordingly (van Manen, 1997, p. 20).

The conversational approach was also inspired by Merleau-Ponty's emphasis on the relational body. In this perspective, communication is regarded as dynamic and intersubjective in the sense that one's own body and the lived body of others share a basic reciprocity:

Whether it is a question of another's body or my own, I have no means of knowing the human body other than that of living it, which means taking up on my own account the drama which is being played out in it, and losing myself in it. (2002, p. 231) 
Such a stance implies that the researcher and participant are likely both to create access to and limit the knowledge developed in an empirically oriented research project (Engelsrud, 2005). In our study, the researcher tried to be sensitive to the women's reactions to various questions, as well as situations or episodes that they found difficult or problematic to talk about. One of the topics which often appeared to be sensitive was the women's experiences with dietary changes after the surgery. Indeed, one of the women started to cry when she talked about it, but when the interviewer reached out to turn off the tape, she shook her head to indicate that the tape recorder could keep going. Another woman became acutely ill during the interview and had to rush to the toilet. Upon returning more than 20 minutes later, she explained that she had "dumped" due to the coffee she had been drinking at the start of the interview. At this point, the researcher became aware that the symptoms they were discussing were actually happening during the conversation. The woman explained that such episodes were a common part of her life now, and that she was happy to continue the interview after the "dumping" episode. These examples disclose how inter-subjectivity during the interview process was intertwined with the knowledge which was developed and found to be significant by the researcher (Finlay, 2002).

Many contemporary phenomenologists argue that researchers should critically engage their own subjectivity in the analytical process (Finlay, 2011; Todres, 2007; Engelsrud, 2005; Walsh 2004). As noted, the first author began to do this during the interview process, when "dumping" emerged as a topic that the women were eager to share with her. After the interviews were transcribed into written texts we pursued this analysis more systematically. To avoid abstract generalizations, we focused on the women's first-person accounts, recorded in everyday language (Finlay, 2011; Dahlberg, Gjengedal \& Råheim, 2010). Inspired by van Manen’s "selective reading process" we posed questions such as: what statements, phrases, or described episodes seem particularly connected to the experience of "dumping"? How do the women use "dumping" as a term that describes their bodily experiences? And finally, how do the women themselves regard and relate to these experiences? Statements and episodes that dealt with these questions were then highlighted in different colors and given different thematic headings.

Collaborative discussions can be helpful in generating deeper insights and understandings (van Manen, 1997). We found, for example, that "dumping" was manifested as both an individual inner body phenomenon and an inter-relational phenomenon. Moreover, we discovered that "dumping" was experienced as uncomfortable bodily reactions that were entwined with the women's efforts to change their eating their habits. These realizations enabled us to move beyond the participants' self-understandings while acknowledging their experiences as unique and essential to our findings. This dialectic of closeness and distance underscores van Manen's point that writing and re-writing - which is at the heart of the analytic process "separates the researcher from the known," but gives her the opportunity to "reclaim this knowledge" and make it her own in a new and more intricate manner (van Manen, 1997, p. 127).

Our discussions also involved a contextual analysis of the women's experiences (Fangen, 2008; Kvale \& Brinkman, 2009). This approach enabled us to scrutinize how the body - and the women's experiences of their bodies - could also be taken to express cultural meanings and ideas. We thus recognized the body as an expression of discursive practices that surround obesity and weight surgery in general, without losing sight of non-discursive experiences that could be sensed in the lived and living body. This ambivalent interaction between body and world is central to Merleau-Ponty's perspective. In accordance with his conceptual framework, our approach acknowledged the interrelatedness between women's embodied experiences and their surroundings. 
It should be noted, however, that we did not pursue these various layers and means of interpretation sequentially. Rather, our analysis involved a back-and-forth process, between parts of the material and the whole, as well as between implicit pre-understandings and explicit understandings of various theoretical perspectives as we wrote and rewrote our explorations of the various themes that emerged. Our analytical process resembled the kind of spiral-like journey advocated by van Manen (1997). In hermeneutic traditions rather than creating a "vicious circle," this process creates a "circulus fructuosis" with a potential for continuously developing understanding of meaning (Kvale \& Brinkman, 2009, pp. 210-211).

\section{Learning to Live as a Changed and Changing Body}

We developed three core themes during our analytical process: 1) Experiences of illness in conjunction with eating. 2) Learning to relate to changes in the inner body. 3) Feelings of losing and regaining control. In different, though interconnected ways, these themes encompass an ongoing challenge in the women's lives after the surgery: namely, their efforts to establish new eating habits while at the same time working hard to relate to their changed and changing inner body, and especially to the phenomenon of "dumping”.

\section{Experiences of Illness in Conjunction with Eating}

The women - who before their operations could eat whatever they desired - experienced, in the post-operative phase, nausea, sweating, palpitations, chest pains, dizziness, trembling, diarrhea, abdominal cramps and pains in conjunction with eating. These complaints were intense and uncomfortable, and several patients felt very ill, as aptly expressed by Una:

I can become very ill. I can ....experience some very uncomfortable side effectsdiarrhea and ....those kinds of things.... Or...what often happens with me is that I break out in a cold sweat... I feel very warm and nauseous.

The discomfort was commonly described as intense throughout the entire body. There was no clear place where it began or ended, and no precise centre. The entire body was permeated by pain and discomfort. The women underlined the discomfort that accompanied these sensations with expressions such as "devilishly uncomfortable," "awful," and "terrifying." Moreover, they explained how the intensity of these sensations forced them to lie down. Additionally the women emphasized that having these acute complaints while at the same time caring for children was problematic. Cille - a mother of three - recounted a recent episode. She was shopping with her son and suddenly became ill after having eaten a little popcorn. Cille fainted in the shop and was awakened by a shop assistant who tried to give her some water. Her son stood by her side, terrified, and had to be calmed down and reassured that this was not a dangerous situation. The women shared the experience that one of the greatest challenges after the operation was the fact that the children were involved in dramatic situations of this kind.

The first episodes involving "dumping" were commonly described as "shocking" or "near death" experiences. Even though the women had been informed by their surgeon about this sideeffect, they felt unprepared for the sudden intense pain and discomfort that accompanied it. Tina recalled this in the following way. It was summer and she was looking forward to eating ice cream in the beautiful weather. However, after a few bites, she became aware of a vague, aching 
pain that increased in intensity. She recalled that towards the end of the episode the pain was so intense that she thought she would die.

The pain overshadowed everything in "dumping" situations. These unavoidable sensations forced the women to concentrate on what was happening inside of them. In Tina's example, the diffuseness and intensity of the symptoms made her fear that there was something seriously wrong inside her body, because she had never felt such sensations before. However, bearing in mind the ice cream she had eaten, Tina quickly reasoned that it had to be "dumping" that caused it. In a similar vein, Stine emphasized that the episodes of illness were most likely to occur when she ate the wrong food: Dumping is what you can get after you eat the wrong kind of food... sweet or fatty foods... it is a physical reaction in the body.

These accounts show how the women conceptualized pain as "dumping" - a bodily reaction that was triggered because they ate too much or the "wrong" type of food. Additionally, the women explained how their episodes of "dumping" were accompanied by an intense exhaustion that forced them to lie down. Lisa described this in the following manner:

You feel that your body is very heavy... I went upstairs and lay down on the sofa, and I just passed out. But the strange thing was that as I lay on the sofa, I couldn't feel my body at all. Everything was simply absent. I couldn't feel where my legs were or anything. My entire focus was on sleeping and getting away from what was going on in my body....

Thus, the self-recrimination for eating the wrong food faded away when tiredness occurred. When the focus changed to sleeping, the body got rest, which was a valuable break from the negative sensations associated with "dumping"

\section{Learning to Relate to Changes in the Inner Body}

In order to avoid episodes of "dumping”, the women spent a lot of time and energy exploring what they could or could not eat, how much and how often. Vivian, for example, elaborated on her intense stomach pain after eating boiled eggs for breakfast. After several experiences with the same kind of pain, she concluded that she could no longer tolerate boiled eggs:

$I$ ate soft-boiled eggs some mornings, and then I got terrible abdominal pains......And that is when I started thinking I'm reacting to eggs maybe...' And then I tried again... And I experienced just as much abdominal pain.... a stomach ache, that is.

Similarly, Stacy explained that she interpreted the episodes of “dumping” as the body's feedback with regard to what foods she could or could not tolerate. Hence, Vivian and Stacy gradually learned to relate to their inner body as both meaningful and expressive. Similar views were expressed by Tina:

Now I have learned what I can tolerate and not tolerate. .... One needs a lot of proteins. And that helps... that is, if I make sure to have eaten them. I mean, if I'm going to a party or something, I often eat chicken or fish or something before I go so that I have a good base to start with. It allows me to eat a little cake or have a little ice cream or something like that. So... it is simply a matter of experience. 
Yet the process of testing what food they could tolerate and not led to a less varied diet than the women previously enjoyed. Everybody emphasized that they tried to eat protein-rich foods and limit their intake of carbohydrates and fatty foods. Ada, for example, found that her tolerance of fried foods gradually worsened. Three years after the operation, she still had to avoid eating in restaurants because she feared becoming acutely ill, saying:

I can't do that any longer. I have to remove all the fat. If the food is fried in butter, I simply can't eat it. And this has become worse and worse... Oh, it just makes me nauseous.... I get really nauseous.

Others emphasized that their diet had become less healthy because their freedom of choice was restricted in terms of fruits, vegetables and dairy products. However, there was variation among the women in the sense that some could no longer eat vegetables, or fruit, whereas others could no longer tolerate dairy products without experiencing acute illness.

So far, we have highlighted how the women experienced "dumping" in situations which involved food. However, they also experienced episodes of acute illness if they waited too long between their meals. Cathy, for example, explained that eating with enough frequency was a great challenge because her sense of hunger was harder to read than it had been before the surgery:

It happens to me all the time, for example, when I don't eat often enough. Then I get these dumping tendencies... nauseated and fatigued and worn out and that kind of thing.

In a similar vein, Lisa explained how she had to eat by the clock every third hour to avoid illness. If she skipped one of her meals, or postponed it an hour or so, she would usually feel like throwing up. In addition she would tremble in her entire body. The trembling had therefore become a sign that she interpreted as hunger:

I have had... well, problems with my blood sugar. Now, for example, I should eat this crispbread wafer I brought along in my handbag. But now I am drinking this coffee, so that should help a little and keep it [the blood sugar] up. And then suddenly I feel very warm and I start shaking...And so I just have to eat something. And then it takes.... a little time before I get back to normal.

Lisa links her trembling to the regulation of blood sugar, and she thinks that the surgery must have affected her insulin production. Accordingly, she compared her symptoms with the hypoglycemia experienced by diabetics.

Even though the women adjusted their diet, they occasionally experienced unpredictable episodes of illness and discomfort. In fact, they described unpredictability as one of the greatest challenges they faced after the operation. Not only did it give them the feeling of losing control over their food intake, but it also affected their relations with other people. The women spoke repeatedly of the time and energy they had spent in trying to find explanations for the unpredictable "dumping” symptoms that "happened" to them. Had they done something wrong? Could they eat more healthy foods? Should they have been more attentive to what their bodies were trying to tell them? Some wondered whether their day-to-day condition might provide meaningful explanations for this unpredictability. For example, if they had a stressful day and 
felt tired or worn out, they were more likely to become ill. Most of the women, however, said that they struggled to try to understand the cause of the sudden appearance of negative symptoms. Five years after the operation, Mia still experienced this unpredictability, and she had not yet discovered how she could avoid it, saying:

I still try, but I don't know how I should interpret it, because I can be... it can be... I can eat a certain food and everything is fine, and then the next time I can actually get ill from it.

The women said that they could find ways to deal with this unpredictable digestion at home. At work or in public, on the other hand, they regarded it as more problematic. Not only did it make them vulnerable to other people's reactions, but it also challenged their efforts to conceal the fact that they had undergone an operation. As Jennifer described it:

At times it is irritating because you notice that you come in and ... I mean ... dumping is not always suitable for the place or time. There have been ....times I have had this at work, it was very uncomfortable. Because.... I have no place to retreat to. So....... you become so incredibly vulnerable.

The women tried to limit the number of people who knew about their surgery and consequently had to manage the ways in which the "dumping" problems could inadvertently and unpredictably render it visible to others. One solution was to hide in the bathroom at work while the "dumping episode” occurred.

\section{Feelings Associated with Losing and Regaining Control}

In the interviews, the women described feelings of happiness and relief when they were able to avoid "dumping" followed by descriptions of guilt, anger, and self-contempt when they were unable to avoid it. Feelings of self-contempt in situations related to food became more intense after the operation, as compared to previously. All of them were afraid to regain weight and considered the operation their last chance to lose weight permanently. A lot seemed to be at stake, as aptly described by Heidi:

Because you have had the operation, you think that you need to "pull yourself together." You think about... both what you have gone through and what society has given you and things like that. So now I have a much worse conscience whenever I don't stick to my diet. Much, much worse.

Additionally, the women expressed strong feelings of losing control in situations when they experienced illness that could be related to "dumping." Two and a half years after her surgery, Anki was still struggling to limit her food intake. Although she knew the consequences of pushing her limits with regards to how much she could eat, these situations were commonly accompanied by strong feelings of regret, guilt and self-contempt for not being able to control herself:

The problem is that one simply loses control and thinks "Oh, I just have to have a taste, just a little," and then one has a little taste and that leads to another spoonful, and yet another spoonful and then.... suddenly there you are, and you 
regret what you've done.... It turns into self-contempt. It's like: "Here I am again, out of control."

In the interviews, the women used the term "stress dumping" to describe episodes that occurred in situations where they were "stressed" in one way or another (too much to do at work coupled with duties at home, emotional distress, and so on). In such situations they found it more difficult to exercise caution with food, and experienced "dumping” more frequently. Jennifer, for example, explained how she occasionally could "dump" for several days in a row although she claimed to know what she could have done to prevent it. In this way she expressed that "dumping" was sometimes something she did to herself, in contrast to other situations where it was experienced as something that just "happened" to her. For Jennifer, this meant that she every now and then would eat large amounts in a short period of time without really noticing what she was doing. When she perceived "dumping" symptoms throughout her body she would feel extremely ashamed of herself. Jennifer regarded these episodes as evidence that she had "no control" of her food intake, and that she still struggled with her old eating problems. In the interview situation, she elaborated on this by saying:

The operation was not on my head, you know. That's why I point to my head. I wasn't operated on inside here.... There is some underlying process that controls me in a way, so it is not my own will that controls things.... Instead it is my body, in a way.

Feelings of powerlessness and alienation are highlighted in this extract. Jennifer feels that her body is profoundly altered and impossible to control. The aversive experience of "dumping" is perceived as controlling the body. At the time of the interview, Jennifer was seeing a psychologist in order to regain "control over her food intake," as she expressed it. In a similar vein, Heidi described how she would use "dumping" as a means of punishing herself during periods of "emotional distress," as she expressed it. These situations were accompanied by an overwhelming sense of self-contempt for triggering the illness episodes, and Heidi emphasized that her self-contempt had become more troublesome after the surgery. Three years after the surgery her eating problems were so severe that she was treated by a psychologist who was specialized in eating disorders.

Others described how they had developed strategies for avoiding "emotional eating." Vivian learned that she could tolerate several glasses of wine without "dumping," and during the interview she explained that she had become more or less dependant on wine in situations where she felt the need to "eat more than she should and could," as she phrased it. Similarly, Trine had learned that smoking diverted her focus away from food in situations where she felt the urge to eat for comfort. A third woman, Gina, described her own method of gradually becoming good at avoiding "dumping." During the two years that had passed since the operation she had learned to be careful - either by stopping before things progressed so far that an illness episode developed, or by avoiding food she associated with "dumping." In addition, Gina expressed gratitude that the operation had contributed to "better control " of her food intake, since the prospect of "dumping" acted as a kind of "hidden threat". Others, such as Lisa and Kathy, used the phrases "warning system" and "necessary evil" to highlight the usefulness of "dumping” as a threat which reinforced their efforts to maintain food restrictions, and therefore enhanced their sense of control. 


\section{Discussion}

Our findings have revealed that the women were constantly on the alert for signs of pain or discomfort, and that they were preoccupied with relating to their changed and changing body. The bodily changes were experienced as unpredictable and complex. Dramatic changes such as sudden drop of blood pressure, dizziness, fainting, and diffuse stomach pain were all filtered into the same phenomenon, namely "dumping." The sensations that accompanied "dumping” were described as intense and permeating the entire body. The body and its surroundings became blurred, and the pain and discomfort that they associated with "dumping" had no clear place or end, and no precise center. We relate this mixture of the local and the non-local to Leder's analysis of the "inner" body. The viscera have a greatly decreased number and variety of sensory receptors compared to the surface body. Consequently, visceral sensations are often vaguely situated, with indistinct borders, permeating the ambiguous space of the inner body (Leder, 1990).

In order to avoid these adverse bodily sensations, the women spent a lot of time and energy exploring and negotiating with themselves what they could and could not eat, and how much and how often they could eat it. This testing was a lonesome, time-consuming and challenging process. It involved pushing tolerance limits as well as enduring the discomfort and pain that accompanied wrong choices. Leder's notion of "dys-appearance” can help us to deepen our understanding of these experiences. Pain, in particular, places upon the sufferer "an affective call” which has the quality of compulsion. Leder notes that due to this "affective call," the individual's focus is forcibly oriented towards the inner body (p. 70). Hence, it seems reasonable to suggest that the women's viscera changed and redirected their attention from "the exterior" to "the interior," particularly in situations following eating, when they perceived pain and discomfort. Awareness of these aversive sensations prompted them to reflect on their own situation with regards to food and eating in a more specific manner than they had done previous to surgery. Stacy, for example, explained how she learned to limit the episodes of illness thanks to her willingness to endure bodily discomfort. As she put it: For me it is a good thing, because I have to try everything on my own. And then I get feedback ... My body gives me messages.

As pointed out by Leder (1990), the viscera are usually less available to conscious awareness and control than the surface body. However, in situations of bodily change individuals can through a heightened attention - increase their awareness of visceral processes. According to de Beauvoir (2000), women are particularly situated to give priority to processes that involve dwelling on the inner body. Her point is that biological changes during puberty, the menstruation cycle, pregnancy, and birth gradually increase women's awareness of their inner bodies. In other words, this heightened sensitivity towards the inner body might prepare women to be attentive to surgical changes of the viscera. Accordingly, one could argue that our participants were prompted to be attentive to their inner body first and foremost due to the physiological and structural changes that accompanied the surgery, but that their bodily awareness was also anchored in their lived experiences as women. Attentiveness to the viscera enabled them to distinguish between the kinds of symptoms that were associated with the "dumping" and symptoms which were experienced as more ordinary. Gradually they learned how to limit episodes of dramatic sensations such as sudden drops of blood pressure, dizziness, fainting, and intense pain in the stomach region. Hence, by means of repeated bodily efforts, their changed eating habits became embodied knowledge, or "knowledge in the hands," to use MerleauPonty's term (2002, pp. 166-169). He elaborates on this process by underlining the significance of embodied understanding: 
It is the body which understands in the acquisition of habit. ......we say that the body has understood and habit has been cultivated when it has absorbed a new meaning, and assimilated a fresh core of significance. (p. 169)

Habit acquisition can thus be regarded as an experience-based, dynamic process, in which repeated efforts gradually gain significance as they are lived and incorporated into new habits.

In light of this understanding, one could say that the women became "experts" on relating to their changed and changing inner bodies. Each and every one had to deal individually with the challenges that accompanied the threat of "dumping" because the context of the episodes they talked about were manifested differently for each woman. Still, a common perspective on the episodes was that they both limited food choices, and brought on feelings of self-blame, guilt, anger, and self-contempt. Many of them emphasized how such feelings had become more prominent and troublesome after the operation. They experienced more difficulty in restraining various forms of emotional outbursts (especially crying, rage, and mood swings) compared to previously. In the interview situation, these changes were underscored, not only verbally, but also with the aid of facial expressions, facial flushes, altered breathing patterns and seating position. Many of them also used their hands, often to point at their bellies, as a way of sharing the felt and personal emotions deep within them, and that the stomach region somehow was involved. Leder emphasizes the viscera's interrelatedness with the autonomic nervous system, including its hormone regulation, and asserts that a person's visceral state is closely linked to her emotionality. In situations of bodily change or dysfunction, however, she is likely to become more explicitly aware of her emotions - a phenomenon which Leder terms depth dys-appearance (1990, p. 173). Moreover, given that the inner body and the surface body are an intertwined unity, changes in emotionality are likely to be expressed and perceived throughout the entire body.

Merleau-Ponty reminds us that we are situated and involved in a social world. Social ideas and meanings, he argues, always function as a stimulus to our reactions, whether these are positive or negative (2002, p. 422-423). In other words, he posits a dynamic and intertwined relationship between body, self and world. As such, an individual's emotions are shaped by other individuals, social meanings and ideas, including norms and values related to gender. Western culture emphasizes a strong relationship between food, femininity, and self-control (Lupton, 1998). Accordingly, women who fully satisfy their appetite for food run the risk of being perceived as unfeminine. In addition, “obese” women are usually perceived as having an eating disorder, whether they do or not. Their eating habits are automatically interpreted as being "out of control.” Drawing on her personal experiences, Murray (2008) summarizes this argument in the following manner:

A fat woman is always under medical and cultural scrutiny, and never more so than when she eats. The fat woman's relationship with food is thought to be defined by gluttony, addiction, indulgence and a lack of control - these popular attitudes are disturbingly internalized by fat women who often feel self-conscious about eating. (p. 24)

What is highlighted here corresponds with the point made by de Beauvoir that a woman's experiences will develop in an ongoing interaction between demands put on her from society and her own projects within the situations in which she finds herself. In our study, this is particularly evident in the ways the women regarded their illness episodes as a personal issue. Its negative aspects were seen as their own problem and responsibility. Moreover, the women repetitively 
used the term "dump" (a verb in need of a subject) indicating that the episodes of illness were brought about by themselves. Even when they talked about the unpredictability of their episodic illness, they held themselves responsible. In this regard, the women's experiences may underscore the notion of individual responsibility inherent in medical discourses on "dumping." Significant weight loss is regarded as evidence that the surgery is "successful," and this is the outcome that the women considered most important. Moreover, medical "experts" lay the responsibility on the patients themselves - by emphasizing that episodes of "dumping" can be avoided through a change of diet (Ukleia, 2005; Tack et al, 2009). Experiences of episodic illness are not given significance beyond the need to focus more on eating in the "proper manner. We argue that this illustrates a disembodied medical orientation to the experience of illness as such.

Negotiating inner bodily sensations and medical discourses on "dumping" seemed to elicit ambivalent feelings among the women. Not only did they regard (and use) "dumping" as an immensely valuable "weight watcher" or "hidden threat," they also expressed some willingness to live with food restrictions for the rest of their lives. They took this position despite dramatic sensations in their inner bodies, usually intensified by feelings of shame, self-blame and anxiety when they failed to control themselves. Their ambivalence regarding food and "dumping” can be understood as experiences generated by the ambiguity inherent in the intertwinement between their lived bodies and their surroundings. As Merleau-Ponty suggests, "man is in the world, and only in the world does he know himself" (2002, p. xii). In other words, the body not only connects us to the world, but also offers us a way to understand that world, including ourselves and others (Finlay, 2011).

However, although the women expressed ambivalent feelings when they were interviewed in this study, they did not talk about their episodes of "dumping” with friends and colleagues. On the contrary, they would tell "white lies" claiming their weight loss was a result of their ongoing dieting to conceal the fact that they had undergone a weight-loss operation. These "strategies" relate to the stigmatized status of bariatric surgeries in contemporary western society. Physically limiting the body's ability to consume and absorb food is generally viewed as a "quick fix" for those eager for rapid and dramatic results, as opposed to the ideal of controlling one 's body lusts and desires (Throsby, 2008). Losing weight by changing one's lifestyle is associated with selfdiscipline and control. As Lupton (1998) claims:

Not only does a strict dietary regimen demonstrate to others who see one eat that one has a high level of self-control, but it is expected that a 'healthy' diet will result in a slimmer body, thus providing a more permanent sign of self-discipline to all those with whom one comes into contact. (p. 16)

Yet, our findings reveal that dieting was in fact a significant part of the women's lives after the surgery. Relating to the changes in their viscera involved constant monitoring of their diet in order to avoid or limit episodes of "dumping." Therefore, we question whether the gastric bypass should be talked about as a "quick fix." Like the traditional "diet," adapting to the changes made by the gastric bypass procedure involves careful and rigorous attention that makes food the focus of the post-operative individual's daily activities. However, despite these similarities, we must point out one significant difference. After undergoing an irreversible gastric bypass, there is no way back to the "old body." In this situation, the woman cannot decide to quit her diet, nor take a "time out" from it, and thus one's freedom of choice after undergoing the gastric bypass procedure is profoundly restricted. 
Empirical studies have shown that "obese" individuals who have not undergone weight loss surgery, but have participated in interventions that enforce strict diets as a way of losing weight, are commonly caught between proper conduct and free choice. This tension is largely brought about by the healthcare workers in charge of the intervention but also by the participants themselves (Knutsen \& Foss, 2011; Rugseth, 2011). According to Rugseth's study, weekends were experienced as a liberating break from the strict diet the participants had to focus on during the week days. They could occasionally enjoy food together with friends and family members without blaming themselves for eating the wrong food. On the contrary, they justified these social meals as immensely valuable in order to keep focused on the strict dietary rules during the week days (Rugseth, 2011). By contrast, the women in our study did not enjoy this freedom of choice without the risk of episodic illness.

De Beauvoir's argument is that women are situated in a state of tension between immanence and transcendence. "Transcendence" refers to the energies and aspirations that individuals direct towards projects outside the private sphere, while "immanence" is associated with tedious, repetitive work which limits the individual's freedom of choice (de Beauvoir, 2000). Having ongoing diet restrictions enforced by the irreversible changes of a gastric bypass surgery can be related to the notion of immanence. It is also related to immanence because it is, quite literally, within the body. It is a change that cannot be seen or felt by anybody but the woman herself, a force that pulls her attention inward instead of outward. From this perspective, it could be argued that the interrelatedness between the habit body and the spontaneous body is somewhat disrupted (Merleau-Ponty, 2002). After gastric bypass surgery, previous eating habits and the digestive system could no longer be taken for granted. This posed a variety of challenges. Given the interrelatedness of the habit body and the body at this moment, "dumping" can be regarded as an ambiguous situation on the part of the woman to preserve her freedom with regard to food and eating, while at the same time acknowledging the need to accommodate her internal bodily changes. This dynamic exemplifies the continual tension between proper conduct and free choice situated in the sensing and gendered body.

Taken together, our findings indicate that women's experiences with food and eating following weight loss surgery are more complex and ambivalent than previously has been documented. Ogden and colleagues (2005) used qualitative methods and explored how patients described their "food behavior" after weight loss surgery. Of the 15 participants included in their study, 8 had undergone gastric banding and 7 had undergone gastric bypass. According to their findings, the concept of "control” permeated all areas of the interviews, regardless of surgery procedure. Ogden and colleagues concluded that the enforced removal of choice (caused by the surgery) paradoxically enabled the participants to control their food intake. Similarly, in an interview study with 16 participants, Engström and Forsberg (2011) found that weight loss surgery was experienced as a positive turning point with regards to eating habits. More precisely, they concluded that during the first year after surgery, the participants' relationship to food went from complex to balanced and totally transformed: a process that was mainly attributed to the physiological changes caused by the surgery. By contrast, we have revealed ambivalence and various challenges in women's experiences with food and "dumping." For the women who previously struggled with various eating problems the phenomenon of "dumping" seemed to be a double-edged sword in the sense that it was regarded - and used - as a "weight watcher," as well as a powerful reminder that their eating problems continued after surgery. In this regard, our findings also point to a dilemma: namely that the gastric bypass procedure irreversibly alters the anatomy and physiology of a woman's healthy stomach. However, her eating habits cannot be situated in or reduced to a particular organ; they are endemic to the lived and living body, with 
its incorporated history. We argue that this insight is essential to understanding the complexity of the changes and challenges that women experience after bariatric surgery.

\section{Methodological Considerations}

When considering the implications of our findings, it should be noted that the participants' ages ranged from 24 to 54. There are, of course, challenges associated with comparing the experiences of women over such a large age range, given the various lifespan-related experiences that these women have gone through. However, we did not find any generational differences between the women regarding their experiences of "dumping", efforts to understand their changed bodies, and struggles to alter habits accordingly. Moreover, married women with children experienced the challenges related to their illness episodes in ways similar to married women without children. This is not to say that conducting a study of women within a more limited age range - for example women in their forties - would not allow other nuances to emerge that we missed due to our broad range of ages. Nonetheless, our intention was to get a sense of the core themes, including their variation, related to the women's experiences with food and "dumping." In doing so, we also discovered variation in their eating habits prior to the surgery. Indeed, they all compared and contrasted their previous situation with their altered state after the operation. Although the women seemed to have a complex and somewhat problematic relationship with food, only five explicitly volunteered that they had an eating problem or an eating disorder in the years prior to the surgery. The researcher decided not to pursue this question with the other women. She was concerned that raising such a sensitive issue might provoke and offend them at a time when they were already in a vulnerable situation. It could also have suggested that she herself believed they suffered from eating disorders, which could have jeopardized the atmosphere of trust that had developed in the interviews.

These assessments made during the interview process can also be linked to the researcher's background as a physiotherapist. She had extensive experience in speaking with patients who suffered from chronic illness, including pain, functional problems, and muscular tension, while she did not feel particularly competent in talking to patients about their eating disorders. This became particularly evident when the conversation turned to bodily symptoms in the context of "dumping”. Since the researcher knew very little about "dumping” she was eager to explore her patients' bodily experience of this phenomenon. For example, when the women talked about mood swings and shame associated with "dumping," the researcher queried whether these sensations were related to particular situations, or whether they manifested themselves more or less continuously. Furthermore, when the women talked about "dumping” both as something unpredictable and as something they had learned to relate to, she asked them to describe these apparently contradictory experiences in further detail. To justify her insistent and inquisitive approach, the researcher usually emphasized her lack of clinical experience with patients who had undergone weight-loss surgery. At the same time, she explained the research-related importance of bringing to light the patients' own experience of this relatively "tacit" phenomenon. In hindsight, one might say that by de-emphasizing her clinical competence and taking a "naïve" and inquisitive research approach the researcher helped turn the participants into experts on the phenomenon of "dumping". At the same time, these examples demonstrate how the researcher's background had an impact on the reflections she made during the process. In the subsequent process of analysis, these reflections gave an important impetus for further exploring the more implicit and contextual aspects of the women's experiences. In this sense, our findings emerged out of a research-participant relationship that generated a dialogical, interactive and reflexive process (Finlay, 2011; Neumann \& Neumann, 2012). 
The strength of applying phenomenological-hermeneutic methodology in this study has been its ability to capture embodied implications of living with a changed and changing digestive system. In highlighting core themes, included their variations, we have provided deeper insight into the interrelatedness between "dumping" and challenges associated with dietary changes following gastric bypass surgery. We suggest that our study has particularly contributed to the illumination of the more or less enforced bodily efforts involved in adjusting to a changed digestive system. We also argue that the focus on embodied meanings - as a supplement to biomedical and nutritional aspects of gastric bypass surgeries - has enabled us to demonstrate how the phenomenon of "dumping" cannot be uncoupled from the person who has to relate to it on a daily basis and the practices and relations in which she is involved. As such, our study offers a way for health researchers and professionals to deepen their appreciation of the lived body as a source of knowledge.

\section{Conclusion}

By including solely participants who have undergone gastric bypass surgery we have explored specific types of experiences that certain women have of living with a dramatically changed body. The experiences shed new light on the complexity of what these women are negotiating, in terms of adjusting their eating habits to their own bodily well-being after the surgery. The "dumping syndrome" has had a profound impact on their process of adjustment. We have elaborated on the ways that the women learned to situate their experiences within what the medical doctors had told them about the syndrome, as well as how they used "dumping" to learn and relearn about themselves and their bodily reactions. Moreover, our findings show that many different sensations of discomfort, dizziness, trembling, fatigue, loss of consciousness, pain and negative feelings associated with food and meals were blended together into the same collective phenomenon of "dumping”.

Our findings also raise some questions that need to be further explored: How can it be that some women experienced "dumping" when they ate fruits or vegetables, whereas others were unable to tolerate dairy products? Does this indicate that the surgery has different impacts on different women in the sense of contributing to the development of different intolerances for food? Or could it be that "dumping" has become a collective term denoting negative sensations that can be perceived in the inner body? And finally, how can healthcare workers give useful advice and care to women who struggle with eating problems prior to their surgery? Is it likely that these problems will change for the better after the surgery? If so, what does it take to achieve such a change? Taken together, these questions indicate that more empirical research is needed to contribute into contemporary understandings of these issues.

\section{Acknowledgements}

We are grateful to our participants who willingly shared their experiences with us. We are also grateful to the Norwegian Fund for Post-Graduate Training in Physiotherapy for the financial support of our project. Finally, we would like to acknowledge two anonymous reviewers for providing useful comment on our article. 


\section{Endnote}

${ }^{1}$ The ethical principles of the Helsinki Declaration provided the basis for our research process, and the study was approved by the Norwegian Regional Committee for Medical and Health Research Ethics (REF 6.2009.88). Information about the study was given to the participants together with a letter inviting them to participate, including a request to tape the interviews. They were also informed that joining the study was completely voluntary and that they had the right to withdraw at any time. Moreover, they were informed that personal information such as names and identity would not be part of the published material.

During the interviews, the researcher tried to establish an atmosphere of trust so that the women would feel comfortable sharing their personal thoughts and feelings, including those that involved bodily changes. Yet equal weight was given to respecting the participants' dignity so that they would not feel obliged to reveal experiences that they would regret afterwards (Guillemin \& Heggen, 2009).

\section{References}

Bengtsson, J. (2006). A forske i sykdoms og pleieerfaringer. Livsverdensfenomenologiske bidrag. [To explore experiences of illness and nursing. Lifeworld phenomenological research]. Norwegian Academic Press, Høyskoleforlaget.

Bordo, S. (1993). Unbearable weight: Feminism, western culture and the body. Berkely, CA: University of California Press.

Burgmer, R., Grigutsch, K., Zipfel, S., \& Herpertz, S. (2005). The influence of eating behavior and eating pathology on weight loss after gastric restriction operations. Obesity Surgery, $15,684-691$.

Deitel, M. (2008). The change in the dumping syndrome concept. Obesity Surgery, 18, 16221624.

De Beauvoir, S. (2000). Det andre kjønn [The second sex]. Oslo: Pax Forlag A/S.

Engelsrud, G. (2005). The lived body as experience and perspective: methodological challenges. Qualitative Research, 5(3), 267-284.

Engström, M., \& Forsberg, A. (2011). Wishing for deburdening through a sustainable control after bariatric surgery. International Journal of Qualitative Studies on Health and Wellbeing, 6 (1), 1-13.

Fangen, K. (2008). Deltakende observasjon. [Participant observation]. Bergen: Fagbokforlaget.

Ferraro D. R. (2004). Preparing patients for bariatric surgery. Clinical Reviews; 58-63.

Finlay L. (2011). Phenomenology for therapists. Researching the lived world. West Sussex: Wiley-Blackwell. 
Finlay, L. (2009). Debating phenomenological research methods. Phenomenology \& Practice, 3(1), 6-25.

Finlay, L. (2002). Quoting the researcher: The provenance, process, and practice of reflexivity. Qualitative Health Research, 12(4), 531-545.

Fisher B., \& Schauer P. (2002). Medical and surgical options in the treatment of severe obesity. American Journal of Surgery 2; 184 (6B): 9S-16S.

Guillemin, M., \& Heggen, K. (2009). Rapport and respect: Negotiating ethical relations between researcher and participant. Medicine Healthcare and Philosophy, 12(3), 291299.

Hass, L. (2008). Merleau-Ponty's philosophy. Bloomington: Indiana University Press.

Helse-Nord, Helse-Midt-Norge, Helse- $\varnothing$, Helse-Vest, Helse-Sør. Behandling av sykelig overvekt hos voksne (Treatment of morbidly obese adults) Nasjonal Arbeidsgruppe, 2007.

Hofsø, D., E.T. Aasheim, G.S. Jakobsen, R. Sandbu, A.T. Aas, J. Kristinsson, \& J. Hjelmesæth. (2011). Oppfølging etter fedmekirurgi.[Follow-up after weight loss surgery]. The Journal of the Norwegian Medical Association 19(131), 1887-1891.

Jakobsen, G. S., Hofsbø, J., Røislien, J., Sandbu R., \& Hjelmesæth, J. (2010). Who undergoes bariatric surgery? Obesity Surgery, 20(8), 1142-1148.

Kvale, S. \& Brinkman, S. (2009). Interviews: Learning the craft of qualitative research interviewing. Los Angeles, CA: Sage.

Langer, M. (1989). Merleau-Ponty's phenomenology. A guide and commentary. London: Palgrave Macmillan.

Leder, D. (1990). The absent body. Chicago, IL: The University of Chicago Press.

Lupton, D. (1998). Food the body and the self. Thousand Oaks, CA: Sage Publications.

Martin, M., Beekly, A., Kjorstad, R., \& Sebesta, J. (2010). Socioeconomic disparities in eligibility and access to bariatric surgery: A national population-based analysis. Surgery for Obesity and Related Diseases 6, 8-15.

Merleau-Ponty, M. (2002). Phenomenology of perception. New York, NY: Routledge.

Moi, T. (2008). What is a Woman. Oxford: Oxford University Press.

Murray, S. (2008). The “fat” female body. Great Britain: Palgrave Macmillan.

Neumann, C. B., \& Neumann, I. B. (2012). Forskeren i forskningsprosesser. Metodebok om situering. [The researcher in the research process -situatedness in research]. Cappelen Damm. 
Ogden, J., Clementi, C., \& Aylwin, S. (2005). Exploring the impact of obesity surgery on patients' health status: A quantitative and qualitative study. Obesity Surgery, 15, 266-272.

Ogden, J., Clementi, C., \& Aylwin, S. (2005). The impact of obesity surgery and the paradox of control. Psychology and Health, 21(2) 2006, 273-293.

Rugseth, G. (2011). Overvekt som livserfaring - et empirisk-teoretisk kunnskapsbidrag. (Obesity as lived experience - an empirical-theoretical contribution). Published Phddissertation. Oslo: Faculty of Medicine, University of Oslo.

Svenaeus, F. (2000). The hermeneutics of medicine and the phenomenology of health. Steps towards a philosophy of medical practice. Boston: Kluver Academic Publishers.

Tack, J., Arts, J., Caenepeel, P., De Wulf, D., \& Bisschops, R. (2009). Pathophysiology, diagnosis and management of postoperative dumping syndrome. Gastro-\& Hepatology, 6 , 583-590.

Throsby, K. (2008). Happy re-birthday: Weight loss surgery and the 'new me.' Body \& Society, 14(1), 117-133.

Todres, L. (2007). Embodied enquiry. Phenomenological touchstones for research, psychotherapy and spirituality. Basingstoke, UK: Palgrave Macmillan.

Ukleia, A. (2005). Dumping syndrome: pathophysiology and treatment. Nutrition in Clinical Practice; 20, 517-525.

Van Manen M. (1997). Researching lived experience: Human science for an action sensitive pedagogy (2nd ed). London, ON: The Althouse Press.

Walsh, R. (2004). The methodological implications of Gadamer's distinction between statements and speculative language. The Humanistic Psychologist, 32, 105-119.

Wysoker, A. (2005). The lived experiences of choosing bariatric surgery to lose weight. $J$ Am Psych Nurses Assoc; 11(1), 26-34.

Zahavi, D. (2003). Faenomenologi. [Phenomenology] Samfundslitteratur, Roskilde Universitetsforlag. 